\title{
Nonradiating Edges Gap-Coupled Multiple Resonator Dual and Tri-Band Microstrip Antennas
}

\author{
V.V.Mapare \\ Sinhgad Institute of Technology \\ opp. Mumbai-Pune expressway \\ Lonavala. Dist.Pune.
}

\author{
S. V. Mapare \\ Sinhgad Institute of Technology \\ opp. Mumbai-Pune \\ expressway \\ Lonavala. Dist.Pune.
}

\author{
G.G.Sarate, PhD. \\ Government polytechnic \\ Amravati.
}

\begin{abstract}
A rectangular microstrip antenna for dual band and tri-band is developed using a parasitic technique. Single rectangular microstrip is splitted into multiple resonators along the width and gap coupled to non-radiating edges. The proposed structure gives sufficient separation between the operating frequencies increasing bandwidth for dual band and tri-band. It covers the frequency range from $1900 \mathrm{MHz}$ to $3 \mathrm{GHz}$ covering Universal Mobile Telecommunication System (UMTS, 1920-2170 MHz), Wireless Local Area Network (WLAN, 2400-2483.5 MHz) and low band Worldwide Interoperability for Microwave Access (WIMAX, 2.5 to 2.8 $\mathrm{GHz}$ ). Simulation results are presented and discussed.
\end{abstract}

Key words: Dual band rectangular microstrip antenna, gap coupled rectangular microstrip antenna, multiple resonators, parasitic resonators, triple band rectangular microstrip antenna.

\section{INTRODUCTION}

Modern communication systems, such as those for satellite links (GPS, vehicular, etc.), as well as emerging applications, such as wireless local networks (WLAN), often require compact and low-cost antennas for dual and multifrequency bands [1]. The design of a microstrip patch antenna with different shapes to create multi-band has been achieved by using different shaped-slots [2]-[5],[10]. The characteristic feature of gap coupled microstrip antennas (MSAs) is that they generate multiple resonances. The separation between these resonances depends to a greater extent on the resonant frequencies of the individual resonators, and also to some extent on the gap and the feed point location [9]. Dual and triband operation is realized by splitting rectangular microstrip antenna (RMSA) into smaller resonators. The number of resonances increases as the number of the resonators increase. By appropriately keeping the difference between resonant lengths of the parasitic resonators and gap width, it is possible to obtain dual and triple frequency operation. This paper deals with multiple resonators that are formed by splitting a single rectangular microstrip antenna along the width where optimizing the gap coupling and resonating lengths of resonators yields dual and tri-band frequency operation. Of these smaller resonators, one of the resonators is co-axially fed while other parasites are gap

coupled to non-radiating edges [7],[8]. Then, the lengths of the individual parasitic resonators are varied so as to sufficiently increase the separation between the resonances to obtain satisfactory dual and tri-band frequency operation. The RMSA is splitted up to twelve smaller resonators, and the performance of each is investigated in detail. For configuration starting with six resonators, dual and triple frequency bands are obtained with sufficient separation between the frequency bands. Similarly, as the number of resonators increases, these configurations show increase in the bandwidth [9] and the frequency ratio.

\section{DUAL \\ AND \\ TRI-BAND FREQUENCY OPERATION USING GAP COUPLED RMSA RESONATORS}

Initially, a single RMSA resonant configuration, as shown in Fig.1, is designed to resonate at the frequency of $2 \mathrm{GHz}$. The patch dimensions are calculated from formulas in [5] as follows: $\mathrm{L}=35 \mathrm{~mm}$ and $\mathrm{W}=46.07 \mathrm{~mm}$. The substrate thickness $\mathrm{h}=0.159$ and dielectric constant $\mathrm{Cr}=4.3$ are used. These yield a bandwidth of $48 \mathrm{MHz}$ when the resonator is fed at $\mathrm{x}=8.9 \mathrm{~mm}$ using $\mathrm{N}$ type coaxial connector of diameter $\mathrm{d}$ $=3 \mathrm{~mm}$.

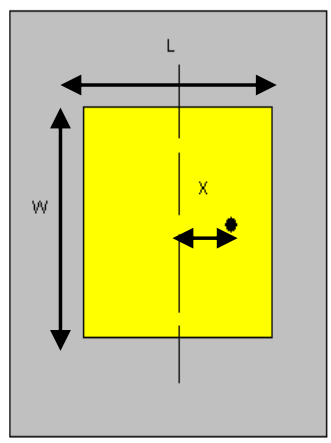

Fig. 1. Configuration of single resonators.

\section{1 .Configuration with six resonators for dual and tri- band operation:}

The single RMSA as shown in Fig. 1 of length $\mathrm{L}=35 \mathrm{~mm}$ and width $\mathrm{W}=46.07 \mathrm{~mm}$ is splitted into six resonators along the width. The widths of the parasitic resonators are equal to that of the fed resonator. The lengths of the parasitic resonators are different; the gap coupling is controlled by the gap-width between the resonators and by properly adjusting the feed point results in the dual band frequency. There are six resonators in the system as shown in Fig. 2; they are asymmetrical about the feed point. Of the six equi-width resonators, the $3^{\text {rd }}$ resonator is fed using a co-axial probe, while the other five act as parasitic resonators that are gap coupled to their non-radiating edges. If the resonating length is the same for all six elements, they radiate at almost same frequency. But for dual band, only two frequency bands with sufficient separation are required. Decreasing the gap width between the $3^{\text {rd }}$ and $4^{\text {th }}$ resonators and increasing the resonating length of the $4^{\text {th }}$ resonator increase coupling between the resonators which result in the combination of 
their resonances. The resonating lengths of the $2^{\text {nd }}$ and $5^{\text {th }}$ resonators are decreased to suppress the individual frequency band together with increasing the gap width which reduces the coupling and increases the frequency difference between the two resonant frequencies which in turn increases the frequency ratio. The $1^{\text {st }}$ and $6^{\text {th }}$ parasitic resonators have the same length, and also the gap widths from the corresponding resonators are the same so that they resonate at the same frequency. Table 1 gives the details of various parameters used in this configuration.

Table 1. Six resonators for dual frequency response $(\mathrm{Gr}=4.3, \mathrm{~h}=1.59 \mathrm{~mm}, \tan \delta=0.02, \mathrm{~W}=7.68 \mathrm{~mm})$

\begin{tabular}{|l|l|l|l|l|}
\hline $\begin{array}{l}\text { Lengths, } \\
\text { L } \\
(\mathbf{m m})\end{array}$ & $\begin{array}{l}\text { Gaps, } \mathbf{S} \\
(\mathbf{m m})\end{array}$ & $\begin{array}{l}\mathbf{f 1} \\
\mathbf{G H z}\end{array}$ & $\begin{array}{l}\mathbf{f 2} \\
\mathbf{G H z}\end{array}$ & $\begin{array}{l}\mathbf{f r}_{2} / \mathbf{f} \\
\mathbf{r}\end{array}$ \\
\hline $\mathrm{L} 1=33$ & $\mathrm{~S}_{1}=2.3$ & & & \\
$\mathrm{~L} 2=31$ & $\mathrm{~S}_{2}=1$ & & & \\
$\mathrm{~L}_{3 \text { fed }}=33$ & $\mathrm{~S}_{3}=0.1$ & 2.085 & 2.53 & 1.21 \\
L4 $=36$ & $\mathrm{~S}_{4}=0.35$ & & & \\
L5 $=31$ & $\mathrm{~S}_{5}=2.1$ & & & \\
L6 $=33$ & & & \\
\hline
\end{tabular}

Simulations are performed for the presented configuration for the dual frequency operation.

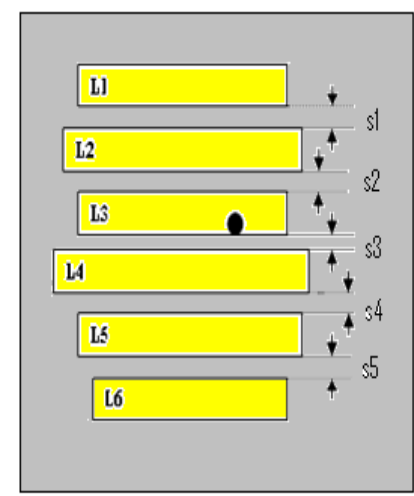

Fig. 2. Configuration of six resonators.

The antennas are fabricated using FR4 substrate with parameters, $\mathrm{h}=1.59 \mathrm{~mm}, \mathrm{Cr}=4.3$, and $\tan \delta=0.02$. The $3^{\text {rd }}$ resonator is fed at $\mathrm{x}=8.2$ from the centre of the resonator using an $\mathrm{N}$ type co-axial connector of diameter, $\mathrm{d}=2.2 \mathrm{~mm}$. The experimental measured resonant frequencies are $\mathrm{fr} 1=$ $2.085 \mathrm{GHz}$ and $\mathrm{fr} 2=2.532 \mathrm{GHz}$, while simulated two resonant frequencies are fr $1=2.085 \mathrm{GHz}$ and $\mathrm{fr} 2=2.53 \mathrm{GHz}$. The maximum frequencies ratio achieved with the six strip configuration is 1.21. This configuration has resonant frequencies in (UMTS,1920-2170MHz) and (WIMAX,2.5$2.8 \mathrm{GHz}$ ) bands.

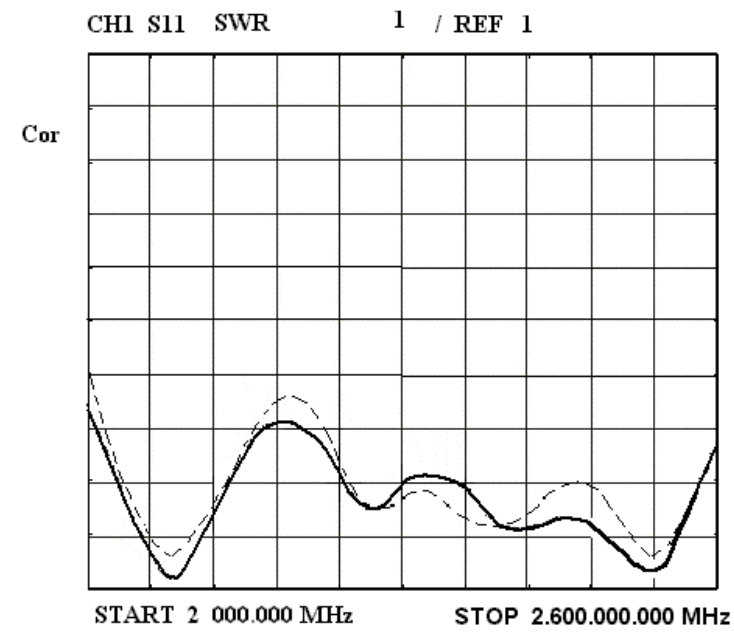

Fig 3. Measured and simulated $S_{11}$ of six resonators for dual frequency operation.

. Fig. 3 shows the comparative plot for the measured and simulated $S_{11}$ for this configuration. Fig. 4 illustrates the radiation pattern plot at two resonant frequencies in $\mathrm{E}$ and $\mathrm{H}$ planes of the six resonators. The radiation pattern at the two resonant frequencies is in the broadside direction.
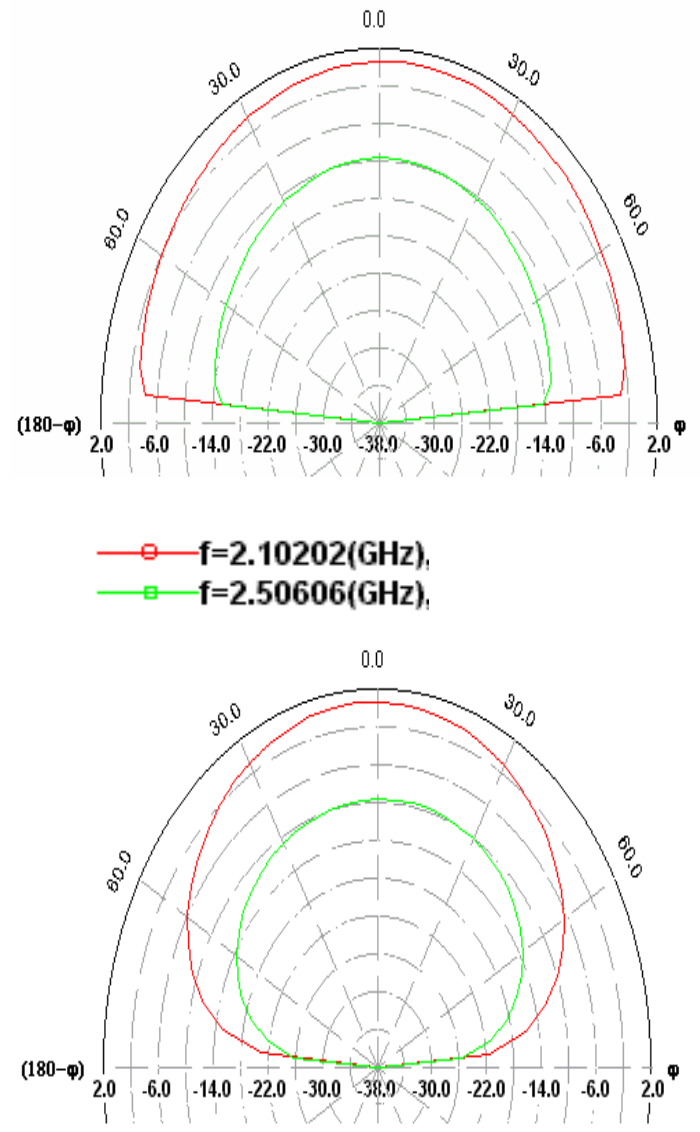

Fig. 4. Radiation pattern plot at two resonant frequencies in $\mathbf{E}$ and $\mathbf{H}$ planes of six resonators. 
Optimizing the length and the coupling gap of the parasitic resonators results in the tri-band operation, the lengths of the $1^{\text {st }}$ and $6^{\text {th }}$ parasitic resonators are the same, they radiate at resonant frequencies closer to each other. The lengths of the $2^{\text {nd }}$ and $5^{\text {th }}$ parasitic resonators are increased along with increasing the gap width as compared to that of the dual configuration to reduce the coupling between the resonances. This results in the separation of the individual resonances, causing an additional frequency band to be obtained. The length of the $4^{\text {th }}$ parasitic resonator is increased to bring its resonance frequency closer to that of the fed resonator. Table 2 gives the information of this configuration including lengths of resonators, the gap width, and resonant frequencies.

Table 2. Six resonators for triple frequency response $(\mathrm{Cr}=4.3, \mathrm{~h}=1.59 \mathrm{~mm}, \tan \delta=0.02, \mathrm{~W}=7.68 \mathrm{~mm})$

\begin{tabular}{|c|c|c|c|c|}
\hline $\begin{array}{l}\text { Lengths } \\
\text { L } \\
(\mathrm{mm})\end{array}$ & $\begin{array}{l}\text { Gaps,S } \\
(\mathbf{m m})\end{array}$ & $\begin{array}{l}\text { fr1 } \\
\text { GHz }\end{array}$ & $\begin{array}{l}\text { fr2 } \\
\text { GHz }\end{array}$ & $\begin{array}{l}\text { fr3 } \\
\text { (GHz } \\
\end{array}$ \\
\hline $\begin{array}{l}\mathrm{L}_{1}=36 \\
\mathrm{~L}_{2}=34 \\
\mathrm{~L}_{3 \text { (fed) }}=36 \\
\mathrm{~L}_{4}=37.5 \\
\mathrm{~L}_{5}=35 \\
\mathrm{~L}_{6}=36\end{array}$ & $\begin{array}{l}\mathrm{S}_{1}=2.2 \\
\mathrm{~S}_{2}=0.2 \\
\mathrm{~S}_{3}= \\
0.15 \\
\mathrm{~S}_{4}=0.57 \\
\mathrm{~S}_{5}=2.47\end{array}$ & 1.967 & 2.209 & 2.373 \\
\hline
\end{tabular}

\subsection{Configuration with seven resonators for dual and tri-band operation:}

The RMSA is further divided into seven resonators, where the $4^{\text {th }}$ resonator is the centre feed. The lengths of the $3^{\text {rd }}, 4^{\text {th }}$ and $5^{\text {th }}$ parasitic resonators are optimized with minimum gap width for maximum coupling so that they resonate at same frequency. The resonating length and the gap width of the $2^{\text {nd }}$ and $6^{\text {th }}$ parasitic resonators are increased to cancel their resonance, increasing the separation between the two bands. The resonating lengths of the $1^{\text {st }}$ and $7^{\text {th }}$ parasitic resonators are decreased to increase their resonance frequencies. The frequencies ratio increases to 1.24 . This configuration has the resonant frequencies in (UMTS, 1920-2170MHz) and (WLAN,2400-2483.5MHz) bands.For the triple frequency operation, the resonating lengths of the $2^{\text {nd }}$ and $6^{\text {th }}$ parasites are decreased so that they resonate to add one more frequency band. The lengths of the $1^{\text {st }}$ and $7^{\text {th }}$ parasitic resonators are the same but decreased to increase their resonant frequencies as compared with the dual frequency operation. The lengths of the $3^{\text {rd }}$ and $5^{\text {th }}$ elements are decreased to increase their resonant frequencies so that they resonate at frequencies closer to that of the driven element ( $4^{\text {th }}$ element), and have sufficient separation between the two frequencies for the dual frequency operation. There is an increase in the bandwidth of the individual frequency bands.

\subsection{Configuration with eight resonators for dual and tri- band operation:}

The eight resonators yield the frequencies ratio of 1.27 and as well increase the individual bandwidth of the resonant frequencies as compared with the six and the seven configurations. The resonating lengths of the $1^{\text {st }}, 2^{\text {nd }}, 7^{\text {th }}$ and $8^{\text {th }}$ parasites are almost the same but decreased from that of the single RMSA, increasing the gap width which resonates at the same frequency. The resonating lengths of the parasites $3^{\text {rd }}$ and $6^{\text {th }}$, also gap coupling are increased to contribute to the frequency band separation. The $4^{\text {th }}$ resonator is fed at $\mathrm{x}=$ $7 \mathrm{~mm}$ from the center with a co-axial connector. The gap width is minimized between the $4^{\text {th }}$ and $5^{\text {th }}$ resonators along with decreasing of the resonating length of the $5^{\text {th }}$ parasite. The simulated return loss is shown in Fig. 5. The structure is fabricated using FR4 substrate with parameters, $\mathrm{h}=1.59 \mathrm{~mm}$, $\mathrm{\epsilon r}=4.3$, and $\tan \delta=0.02$. The measured frequencies are $\mathrm{f}_{\mathrm{r} 1}=$ $2.11 \mathrm{GHz}$ and $\mathrm{f}_{\mathrm{r} 2}=2.695 \mathrm{GHz}$. The simulated frequencies are $\mathrm{f}_{\mathrm{r} 1}=2.1 \mathrm{GHz}$ and $\mathrm{f}_{\mathrm{r} 2}=2.7 \mathrm{GHz}$.

The resonating lengths of the parasites $1^{\text {st }}, 2^{\text {nd }}, 7^{\text {th }}$ and $8^{\text {th }}$ are increased so that the $2^{\text {nd }}$ and $7^{\text {th }}$ parasites resonate at the same frequency. When the difference between the resonating lengths of the resonators is less multiple resonances occur. Optimizing the resonating lengths of the parasites along with gap coupling results in tri-band operation. However, although the separation between resonances is increased, the increase in bandwidth becomes significantly less than the previous case. As can be seen from Fig. 6, the radiation pattern of all the three frequency bands are in broadside in $\mathrm{E}$ and $\mathrm{H}$ planes Fig. 7 shows the comparative plot of the return loss for seven and eight resonators for the tri-band operation. The simulation results yield an increase in the separation of the individual frequency bands with an increase in the number of resonators.

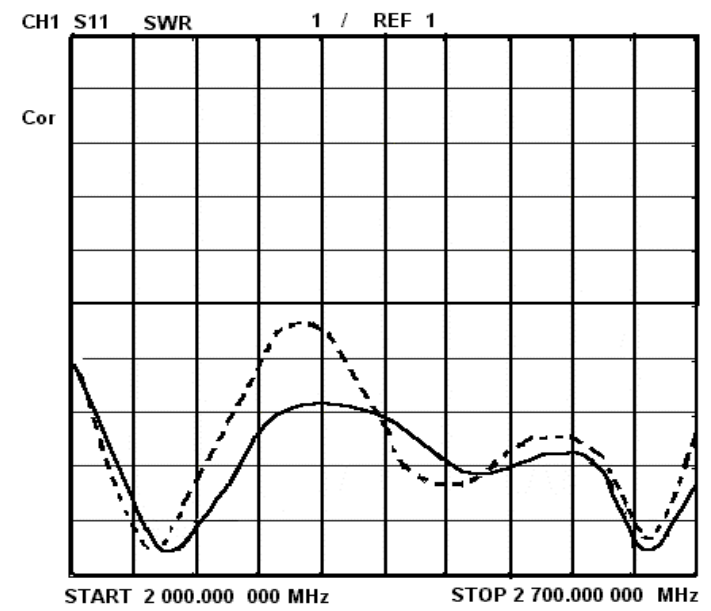

Fig. 5. Measured and simulated $S_{11}$ of eight resonators for dual frequency operation.

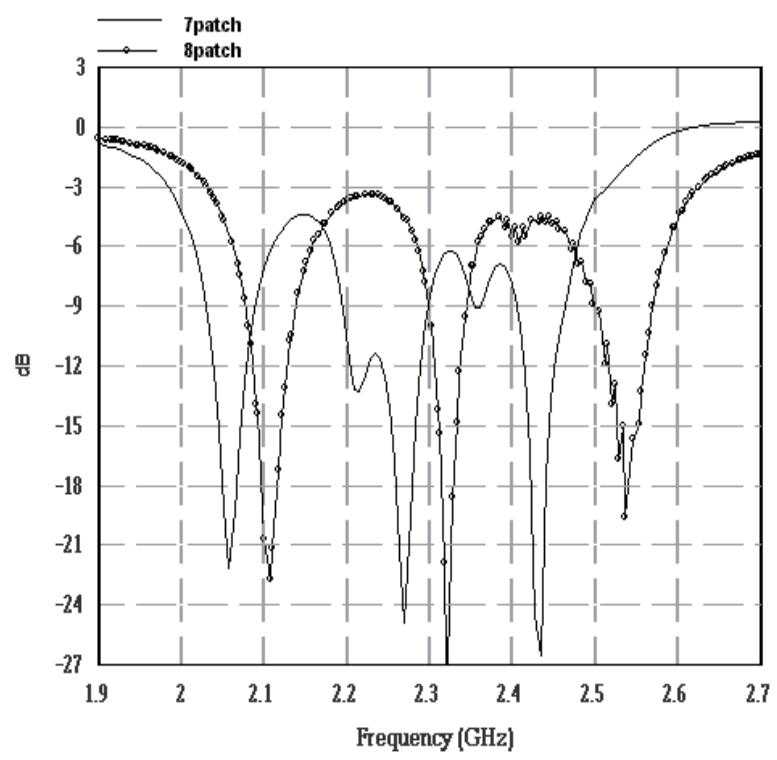

Fig. 7. Comparative plot of return loss for 7 and 8 resonators configuration for tri-band operation. 

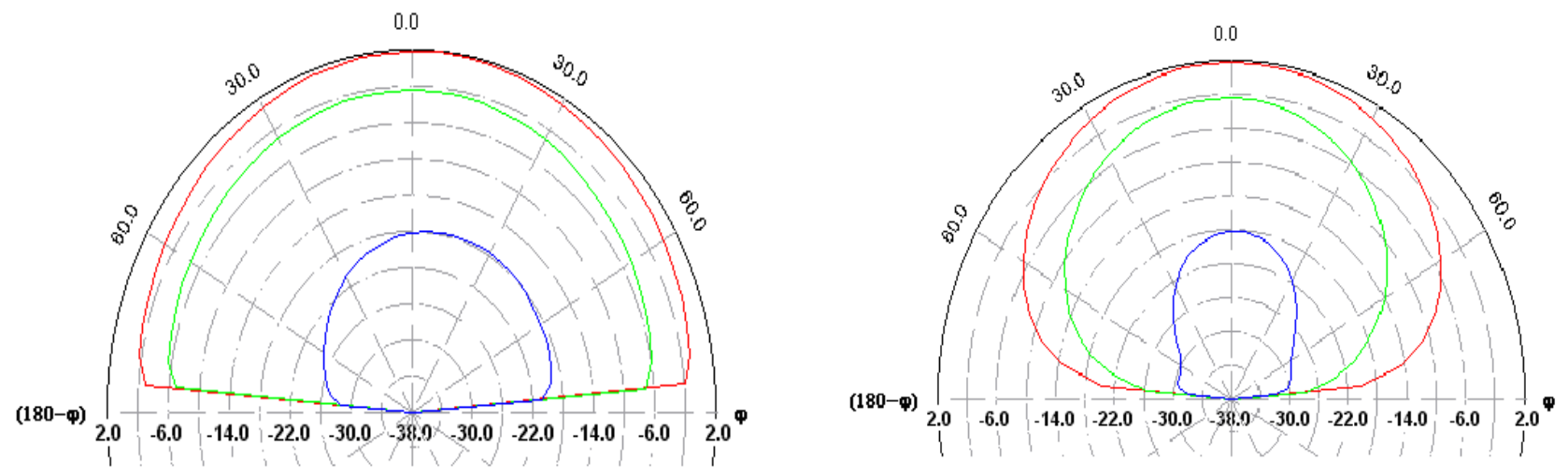

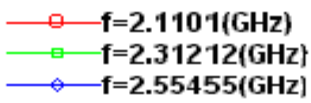

Fig. 6. Radiation pattern plot at three resonant frequencies in $\mathrm{E}$ and $\mathrm{H}$ planes of eight resonators.

\subsection{Configuration with nine resonators for dual and tri-band operation:}

In this configuration, the parasitic resonators are all symmetrical about the $5^{\text {th }}$ fed resonator. The length of the $4^{\text {th }}$ parasitic resonator is reduced and the gap width between the $4^{\text {th }}$ and $5^{\text {th }}$ resonators is decreased so that they resonate at a frequency closer to each other. The gap width between the $4^{\text {th }}$ and $3^{\text {rd }}$ parasitic resonators, along with resonating length of the $3^{\text {rd }}$ and $6^{\text {th }}$ parasites are increased to enhance the frequency separation. The resonating lengths of the $1^{\text {st }}, 2^{\text {nd }}, 7^{\text {th }}$ and $9^{\text {th }}$ are the same so that they resonate at the same frequency together with optimization of gap widths. The frequency ratio of 1.31 is obtained that is higher than the previous cases, but the bandwidth at individual band is reduced.

Tri-band frequency is obtained by increasing the resonating length of the $3^{\text {rd }}$ and $8^{\text {th }}$ parasites and decreasing the gap widths and the resonating length of $6^{\text {th }}$ is reduced. This causes reduction in the coupling results in the tri-band operation. Simulations are performed with this configuration for the triband frequency operation. The configuration is fabricated using FR4 substrate with parameters, $\mathrm{h}=1.59 \mathrm{~mm}, \mathrm{Cr}=4.3$, and $\tan \delta=0.02$. The $5^{\text {th }}$ element is fed at $\mathrm{x}=8.2$ from the center. The measured resonance frequencies are fr1 = $2.07 \mathrm{GHz}$, fr $2=2.317 \mathrm{GHz}$ and $\mathrm{fr} 3=2.549 \mathrm{GHz}$, while the simulated resonant frequencies are fr $1=2.062 \mathrm{GHz}$, fr2 $=$ $2.31 \mathrm{GHz}$ and $\mathrm{fr} 3=2.46 \mathrm{GHz}$. Fig. 7 shows the measured and simulated $S_{11}$ of the nine resonators for the tri-band operation.

\subsection{Configuration with ten resonators for dual and tri- band operation:}

As the number of resonators increases, the number of resonance also increases. The single RMSA is now divided into ten equi-width resonators The resonating lengths of the $1^{\text {st }}, 3^{\text {rd }}$ and $8^{\text {th }}, 10^{\text {th }}$ parasites are the same so that they resonate at frequencies closer to each other by varying the gap widths. While the resonating lengths and the gap width of the $2^{\text {nd }}$ and $9^{\text {th }}$ parasites are increased to decrease the resonant frequencies of these parasites, the resonating lengths of the 4th and $7^{\text {th }}$ parasites are increased to decrease their resonant frequencies to suppress the other bands. The resonating length of the $6^{\text {th }}$

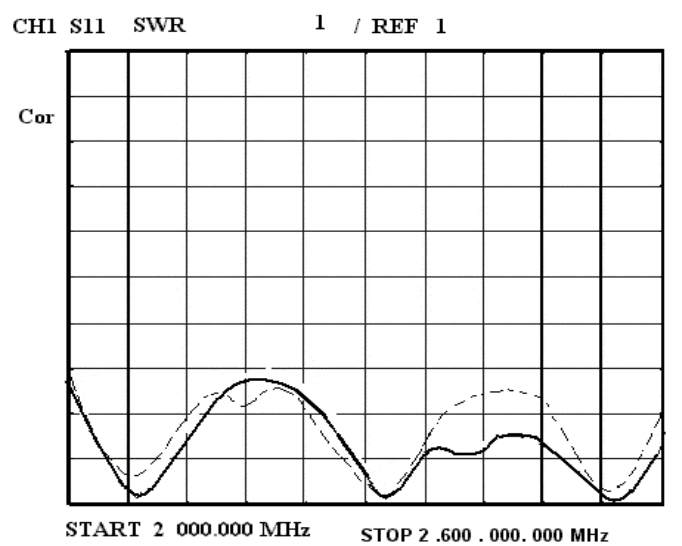

Fig. 8. Measured and simulated $S_{11}$ of nine resonators for tri-band operation.

parasite is decreased to increase its resonant frequency bring it closer to that of the fed element ( $5^{\text {th }}$ element). The frequencies ratio is increased to 1.33 . The bandwidth of the two frequency bands is reduced to $47 \mathrm{MHz}$ and $30 \mathrm{MHz}$. For the triple band operation, the length of the $1^{\text {st }}$ parasite is increased so that the $1^{\text {st }}, 2^{\text {nd }}$ and $3^{\text {rd }}$ resonators resonate closer to each other. The resonant frequencies of the $8^{\text {th }}, 9$ th and $10^{\text {th }}$ parasites add up to resonate at the same frequency. The parasitic length of the $4^{\text {th }}$ resonator is decreased to match its resonant frequency to that of the fed $\left(5^{\text {th }}\right.$ resonator) resonator and that of the $6^{\text {th }}$ resonator. The separation between the individual frequency bands is increased compared with that of the previous case.

\subsection{Configuration with eleven resonators for dual and tri- band operation:}

Now, the single RMSA is divided into eleven strips, the resonating lengths of the $1^{\text {st }}, 2^{\text {nd }}$ and $11^{\text {th }}$ parasites are the same so they resonant at frequencies closer to each other. The resonating lengths of the $3^{\text {rd }}, 4^{\text {th }}, 5^{\text {th }}, 8^{\text {th }}, 9^{\text {th }}$ and $10^{\text {th }}$ parasites are increased to decrease their resonant frequencies and provide significant separation between the two resonant frequency bands. The resonating length of the $7^{\text {th }}$ parasite is decreased to increase its resonant frequency to match to that 
of the fed ( $6^{\text {th }}$ resonator) resonator along with optimizing the gap widths.

Table 3: Comparisons of frequency ratios and bandwidth at dual frequency

\begin{tabular}{|c|c|c|c|c|c|}
\hline $\begin{array}{c}\text { No. of } \\
\text { Reson- } \\
\text { ators }\end{array}$ & $\begin{array}{c}\mathbf{f}_{\mathbf{r 1}} \\
\mathbf{G H z}\end{array}$ & $\begin{array}{c}\mathbf{f}_{\mathbf{r} 2} \\
\mathbf{G H z}\end{array}$ & $\begin{array}{c}\mathbf{B W}_{\mathbf{1}} \\
\mathbf{M H z}\end{array}$ & $\begin{array}{c}\mathbf{B W}_{\mathbf{2}} \\
\mathbf{M H z}\end{array}$ & \\
\hline Six & 2.085 & 2.53 & 43 & 43 & 1.21 \\
\hline Seven & 1.998 & 2.474 & 51 & 47 & 1.24 \\
\hline Eight & 2.10 & 2.70 & 57 & 60 & 1.27 \\
\hline Nine & 2.078 & 2.722 & 52 & 40 & 1.31 \\
\hline Ten & 2.062 & 2.759 & 47 & 30 & 1.33 \\
\hline Eleven & 2.05 & 2.78 & 87 & 36 & 1.36 \\
\hline Twelve & 2.033 & 2.845 & 32 & 35 & 1.40 \\
\hline
\end{tabular}

The frequencies ratio with this configuration is increased to 1.36 .

For the triple frequency operation, the resonating lengths of the $1^{\text {st }}, 2^{\text {nd }}$ and $3^{\text {rd }}$ parasites are made closer to each other to have the first frequency band. Similarly, the resonating lengths of the $9^{\text {th }}, 10^{\text {th }}$ and $11^{\text {th }}$ parasites yield the second frequency band and the $6^{\text {th }}$ and $7^{\text {th }}$ parasitic resonators resonate to yield the third frequency band. The resonating lengths of the $4^{\text {th }}, 5^{\text {th }}$ and $8^{\text {th }}$ resonators are increased to decrease their resonant frequencies which provide separation between the bands.

\subsection{Configuration with twelve resonator for dual and tri- band operation:}

In configuration with twelve strips, there can be a dual, tri as well as multi frequency operations. Only the dual and trifrequency operations are investigated in this paper.

For the dual frequency operation, the resonating lengths of the $1^{\text {st }}, 2^{\text {nd }}, 3^{\text {rd }}$ resonators are almost equal to that of the $10^{\text {th }}, 11^{\text {th }}$ and $12^{\text {th }}$ respectively, as the parasites with the same lengths resonate at the same frequency. These six resonators along with the gap width variation resonate to result in one single frequency band. The resonating lengths of the $5^{\text {th }}$ and $7^{\text {th }}$ resonators are decreased to increase their resonant frequencies to match that of the fed ( $6^{\text {th }}$ resonator) resonator in the second frequency band. The resonating lengths of the $4^{\text {th }}$, $8^{\text {th }}$, and $9^{\text {th }}$ parasites are increased to decrease their resonant frequencies that enhance the separation between the two resonant frequency bands. With this configuration, the maximum frequencies ratio achieved is 1.4 . The bandwidths at individual frequency bands are just over $32 \mathrm{MHz}$ and $35 \mathrm{MHz}$, respectively. As the difference between the lengths of the different elements becomes large, the separation between the resonances increases yielding a larger frequency ratio. Table 4 summarizes the comparisons of the frequency ratios and bandwidth at dual frequency up to twelve configurations. This configuration has resonant frequencies for (UMTS,1920$2170 \mathrm{MHz}$ ) and (WIMAX,2.5-2.8GHz) bands.

Similarly, for triple frequency operation, the resonating lengths of the $8^{\text {th }}$ and $9^{\text {th }}$ resonators are decreased to have a frequency band between the two previous bands. The resonating lengths of the $10^{\text {th }}$ and $11^{\text {th }}$ parasite are increased to decrease their resonant frequency and increase their separation. However, the separation between the resonances is larger for this configuration than the previous cases.

\section{CONCLUSION}

The nonradiating edges gap coupled microstrip antenna up to twelve resonators yields maximum frequency separation ratio of 1.4. At the same time, with increase in the number of parasitic resonators, the enhancement in the bandwidth of the individual frequency band is up to configuration of eight resonators. After that. the frequency ratio increases but the bandwidth reduces for dual frequency operation. Similarly for tri-band, it is observed that the separation between the individual band increases with increase in the number of resonators but increase in the bandwidth of the individual frequency band is insignificant. All these configurations are obtained by splitting a RMSA, and the resonating lengths were changed together with the gap widths. Further multiple frequency resonances may be obtained beyond the six resonating configuration by optimizing the resonating lengths of the parasitic resonators and the gap widths between them.

\section{REFERENCES}

[1] H. F. AbuTarboush, R. Nilavalan, K. M. Nasr, Raweshidy, D. Budimir and M. J. Alexander, "A Compact Printed Antenna for Multiband Wireless Applications" IEEE International Workshop on Antenna Technology (iWAT), Lisbon, Portugal. March 2010 pp 1-4.

[2] Pramendra Tilanthe' P. C. Sharma, "Design of a single layer multiband microstrip square ring antenna" Applied Electromagnetics Conference (AEMC) Calcutta, India. Dec. 2009. pp. 1-4.

[3] Yu-Jen Chi, Fu-Chiarng Chen, "Compact Printed heptaBand Monopole Antenna for Mobile Devices" .Microwave Conference Proceedings (APMC), AsiaPacific, Yokohama, Japan. Dec.2010. pp.2216 2219.

[4] W. X. Li, X. Liu, and S. Li, "Design of A Broadband and Multiband Planar Inverted-F Antenna," 2010 International conference on Communications and Mobile Computing, vol. 2,12-14 April 2010.

[5] A. A. Lotfi Neyestanak,Alex Danideh, Reza Sadeghifakhr "Compact size microstrip array mimo antenna operable in multiband". June 2008 pp. $158-161$.

[6] G.Kumar and K.C.Gupta, "Nonradiating edges and four edges gap coupled wth multiple resonator, broadband Microstrip antennas", IEEE Trans. Antennas Propagation 33 (1985), 173-178.

[7] G.Kumar and K.C.Gupta,"Broadband Microstrip antennas using additional resonators gap coupled to the radiating edges", IEEE Trans. Antennas Propagation 32

(1986), 1375-1379.

[8] K. P. Ray ,G. Kumar, “ Multifrequency and broad band

hybrd-coupled circular microstrip antennas”, Electronic Letter 33 (1997), 437-438.

[9] K.P.Ray and G.Kumar, "Compact gapcoupled shorted $90^{\circ}$ sectoral Microstrip antennas for broadband and dual band operations", Microwave \& Optical Tech. Letters 26 (2000), 143-145.

[10] G.Kumar and K.P.Ray, Broadband Microstrip antennas, Artech House, Boston, 2003. 